\title{
Identification of a potent antagonist of smoothened in hedgehog signaling
}

\author{
Junwan Fan ${ }^{1,2+}$, Haowen $\mathrm{Li}^{1,2+}$, Lun Kuang ${ }^{3 \dagger}$, Zichen Zhao ${ }^{1,2}$, Wenyan He ${ }^{1,2}$, Chen Liư ${ }^{3}$, Yongjun Wang ${ }^{1,2^{*}}$, \\ Steven Y. Cheng ${ }^{3^{*}}$ and Wei Chen ${ }^{1,2^{*}}$ (D)
}

\begin{abstract}
Background: Hedgehog signaling is essential to the regulation of embryonic development, tissue homeostasis, and stem cell self-renewal, making it a prime target for developing cancer therapeutics. Given the close link between aberrant Hedgehog signaling and cancers, many small molecular compounds have been developed to inhibit Smoothened, a key signal transducer of this pathway, for treating cancer and several such compounds have been approved by the United States Food and Drug Administration (GDC-0449 and LDE-225). However, acquired drug resistance has emerged as an important obstacle to the effective use of these first generation Hedgehog pathway blockers. Thus, new Smoothened inhibitors that can overcome such resistance is an urgent need going forward.

Results: We established the Smoothened/ßarrestin2-GFP high-throughput screening platform based on the mechanistic discovery of Hedgehog signaling pathway, and discovered several active small molecules targeting Smoothened including 0025A. Here we show that 0025A can block the translocation of $\beta$ arrestin2-GFP to Smoothened, displace Bodipy-cyclopamine binding to wild-type Smoothened or mutant Smoothened-D473H, reduce the accumulation of Smo on primary cilia and the expression of Gli upon Hedgehog stimulation. In addition, we show that 0025A can effectively suppress hair follicle morphogenesis and hair growth in mice.
\end{abstract}

Conclusions: Our results demonstrate that 0025A is a potent antagonist targeting Smoothened wild-type and mutant receptors in the Hedgehog signaling pathway and may provide a new therapy for refractory cancers.

Keywords: 0025A, Antagonist, Cancer, Hedgehog signaling, Primary cilia, Smoothened mutation

\section{Background}

Originally discovered in Drosophila melanogaster, the evolutionarily conserved Hedgehog (Hh) signaling pathway plays critical roles in promoting embryonic development $[1,2]$. Upon completing embryogenesis, this pathway mostly becomes dormant except in certain tissues and under specific conditions such as during hair

\footnotetext{
*Correspondence: yongjunwang@ncrcnd.org.cn; sycheng@njmu.edu.cn; wei. chen@ncrcnd.org.cn

† Junwan Fan, Haowen Li and Lun Kuang contributed equally to this work

${ }^{1}$ China National Clinical Research Center for Neurological Diseases, Beijing Tiantan Hospital, Capital Medical University, Beijing 100070, China

${ }^{3}$ Department of Developmental Genetics, School of Basic Medical

Sciences, Nanjing Medical University, Nanjing 210000, Jiangsu, China

Full list of author information is available at the end of the article
}

follicle morphogenesis and tissue repair [3, 4]. It has reported that Hh signaling is essential for regulating growth and morphogenesis of hair follicle [5].

Currently, it is known that the transduction of Hh signaling is regulated through Ptch1-Smo-Gli1 [6-8]. In the absence of Hh ligands, the twelve-transmembrane receptor Patched1 (Ptch1) suppresses the activity of seventransmembrane receptor Smoothened (Smo), which is homologous to the G-protein coupled receptors, and leads to negatively regulate the $\mathrm{Hh}$ signaling pathway. However, in the presence of Hh ligands, Hh ligands directly bind to Ptch 1 and alleviate its inhibition of Smo [9-11]. As a consequence, the activated Smo promotes Gli transcription factors to translocate into nucleus and regulates target genes expression.

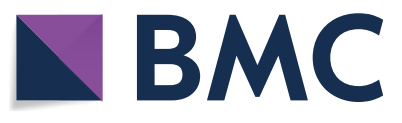

(c) The Author(s) 2021. This article is licensed under a Creative Commons Attribution 4.0 International License, which permits use, sharing, adaptation, distribution and reproduction in any medium or format, as long as you give appropriate credit to the original author(s) and the source, provide a link to the Creative Commons licence, and indicate if changes were made. The images or other third party material in this article are included in the article's Creative Commons licence, unless indicated otherwise in a credit line to the material. If material is not included in the article's Creative Commons licence and your intended use is not permitted by statutory regulation or exceeds the permitted use, you will need to obtain permission directly from the copyright holder. To view a copy of this licence, visit http://creativeco mmons.org/licenses/by/4.0/. The Creative Commons Public Domain Dedication waiver (http://creativecommons.org/publicdomain/ zero/1.0/) applies to the data made available in this article, unless otherwise stated in a credit line to the data. 
Aberrant activation of Hh signaling pathway is related to the development of many cancers including basal cell carcinoma (BCC), medulloblastoma (MB) and many solid tumors $[12,13]$. According to recent studies, PTCH1 mutation is the cause of basal cell nevus syndrome (also known as Gorlin syndrome), which significantly increases the risk of patients with $\mathrm{BCC}$ and $\mathrm{MB}[14,15]$. In addition, it has been reported that the inactivation mutation of PTCH1 and the activation mutation of Smo have been found in most spontaneous BCC and MB [16, 17]. Given the close relationship between excessive Hh signaling pathway and cancer, numerous researches have been devoted to design and synthesize small molecule inhibitors of Smo for treatment of cancers [18-20].

The transmembrane protein Smo is the main transducer of Hh signaling pathway and can be used as an important drug target $[21,22]$. Thus far, there are many Smo inhibitors have been under investigation in clinical trials. Among them, GDC-0449 (vismodegib) was approved by FDA for treatment of advanced BCC in 2012 [23-25]. Unfortunately, a recurring case revealed the drug resistance to GDC-0449 due to Asp473 to His mutation $(\mathrm{D} 473 \mathrm{H})$ in Smo, which would suppress the interaction between drug and receptor [26, 27]. In addition, reports indicated that about 40\% BCC patients acquired drug resistance carry the Smo mutations. Of these, $17 \%$ patients contained the Smo-D473H type [28]. Therefore, new Smo inhibitors that could inhibit wild-type and mutant receptors are essential for overcoming drug resistance.

Previous reports have demonstrated that $\beta$-arrestins are cytosolic adapter proteins, which would form complexes with most activated seven-transmembrane receptors after the receptors were phosphorylated by G-protein coupled receptor kinases [29]. Our preliminary results have shown that constitutively active wildtype Smo could recruit $\beta$ arrestin2-GFP ( $\beta$ arr2-GFP) to the plasma membrane [10]. $\beta$ arr2-GFP was evenly distributed in the cytoplasm when expressed alone in U2OS cells. Furthermore, co-expressing a chimeric form of Smo (Smo-633) swapping the $\mathrm{C}$ terminus of Smo with vasopressin type 2 receptor and $\beta$ arr2-GFP in cells caused an obvious redistribution of $\beta$ arr2-GFP to intracellular vesicles as aggregates, which could be blocked by Smo antagonist cyclopamine [10, 30,31]. Based on these findings, we constructed the cell-based high-throughput screening assay and searched small molecule chemical libraries for potent Smo inhibitors by using this high-throughput assay. Here we show that several active hits including 0025A are discovered. It can block the translocation of ßarr2-GFP to Smo, displace Bodipy-cyclopamine binding to wild-type Smo or mutant Smo-D473H, effectively reduce the accumulation of Smo on primary cilia and the expression of Gli upon Hh stimulation as well as suppress hair follicle morphogenesis and hair growth in mice. Our results demonstrate that $0025 \mathrm{~A}$ is a potent antagonist targeting Smo receptors in the Hh signaling pathway and may provide a therapy for refractory cancers.

\section{Results}

\section{Identification of compound 0025A}

As we showed previously, ßarr2-GFP was distributed evenly in the cytoplasm when it was expressed alone in U2OS cells, which are commonly used for high-throughput cancer drug screens [31] (Fig. 1a). However, coexpressing ßarr2-GFP with Smo-633 caused an ostensible redistribution of $\beta$ arr2-GFP to intracellular aggregates/ vesicles as evident by the appearance of bright aggregates surrounding the nuclei (Fig. 1b). Smo antagonist cyclopamine (Сyc) treatment led to the disappearance of green vesicles (Fig. 1c). Addition of Smo agonist SAG in the presence of Cyc led to the reappearance of aggregates of green vesicles (Fig. 1d). The images were quantitated in Fig. 1e. Based on this assay, we built up the primary highthroughput screening assay and screened our propriety small molecules library to identify small molecules that could prevent the-intravesicular aggregation of ßarr2GFP. We found that a lead compound 0025A could be able to inhibit the cellular puncta formation of $\beta$ arr2-GFP (Fig. 2a). The $\mathrm{IC}_{50}$ of $0025 \mathrm{~A}$ and GDC-0449 was $1.7 \mathrm{nM}$ and $28 \mathrm{nM}$, respectively as determined by our screening assay (Fig. 2b). The activity of 0025A on Smo was further validated by $\mathrm{Smo} / \beta \mathrm{arr} 2-\mathrm{GFP}$ internalization assay using Cyc and SAG as controls (Fig. 3). The structure of 0025A
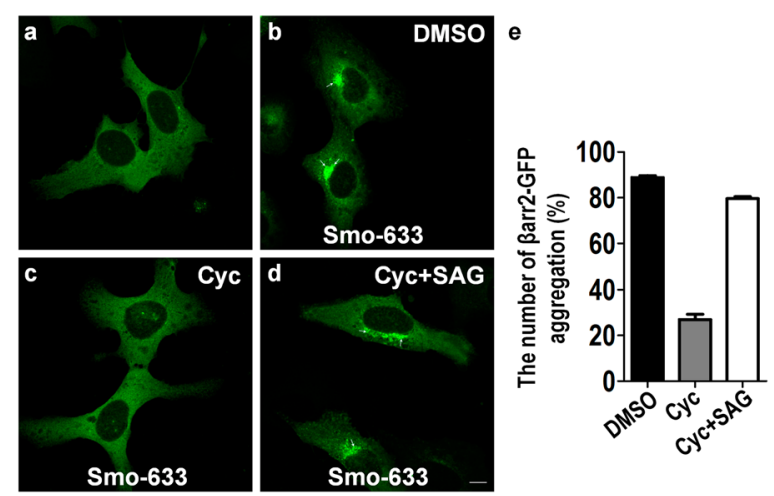

Fig. 1 The translocation of ßarr2-GFP to Smo in U2OS cells. The U2OS cells stably overexpressing ßarr2-GFP alone (a) or ßarr2-GFP and Smo-633 (b-d). Cells were treated with DMSO vehicle (b), $1 \mu \mathrm{M}$ cyclopamine (Cyc) (c), or $1 \mu \mathrm{M}$ Cyc and $1 \mu \mathrm{M} \mathrm{SAG}$ (d) for $24 \mathrm{~h}$ at 37 ${ }^{\circ} \mathrm{C}$. The arrows showed the intravesicular aggregation of $\beta$ arr2-GFP. $\mathbf{e}$ Percentage of the number of $\beta$ arr2-GFP aggregation was quantitated. Scale bar, $10 \mu \mathrm{m}$ 

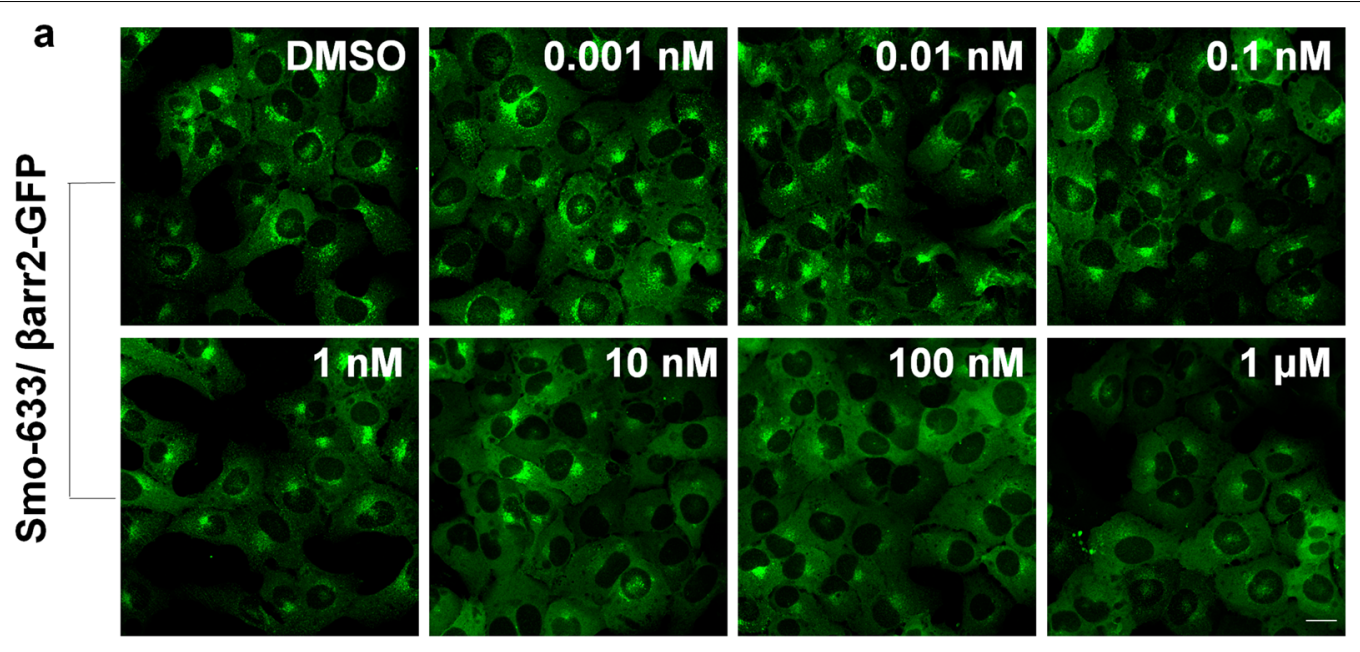

b

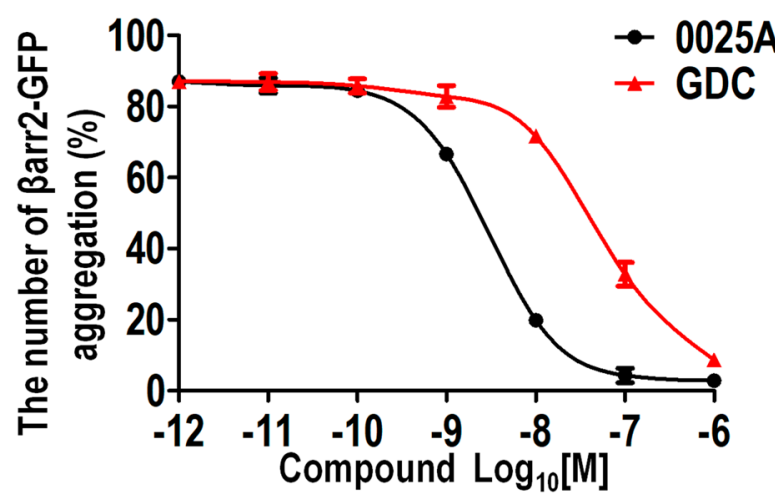

Fig. 2 0025A inhibits the intravesicular aggregation of ßarr2-GFP. a The U2OS cells stably overexpressing ßarr2-GFP and Smo-633 were treated with different concentration of $0025 \mathrm{~A}\left(10^{-12}-10^{-6} \mathrm{M}\right)$ for $24 \mathrm{~h}$ at $37^{\circ} \mathrm{C}$. b Percentage of the number of $\beta$ arr2-GFP aggregation was quantitated. GDC represented GDC-0449. Scale bar, $20 \mu \mathrm{m}$

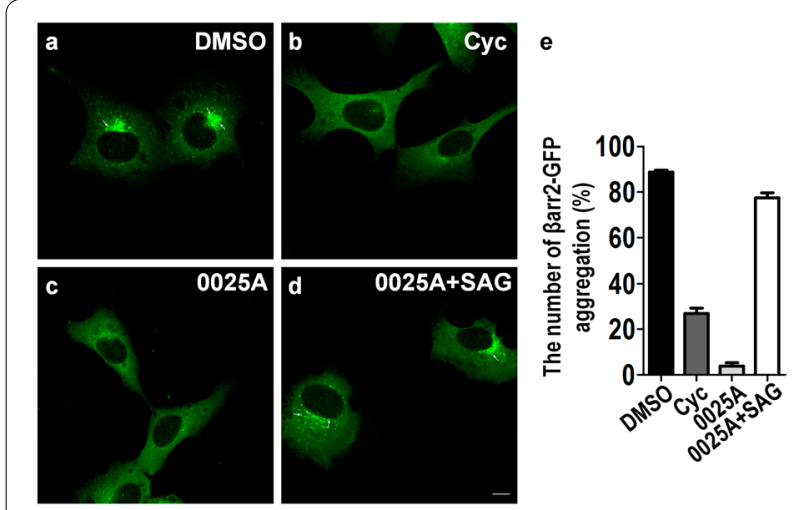

Fig. 3 Identification of novel Smo inhibitors in U2OS cells. The U2OS cells stably overexpressing Barr2-GFP and Smo-633 were treated with DMSO (a), 1 MM cyclopamine (Cyc) (b), $100 \mathrm{nM} 0025 \mathrm{~A}$ (c), or $100 \mathrm{nM}$ 0025A and $1 \mu \mathrm{M} \mathrm{SAG}(\mathbf{d})$ for $24 \mathrm{~h}$ at $37^{\circ} \mathrm{C}$. The arrows showed the intravesicular aggregation of $\beta$ arr2-GFP. e Percentage of the number of $\beta$ arr2-GFP aggregation was quantitated. Scale bar, $10 \mu \mathrm{m}$ is shown in Fig. 4a. It was synthesized using the route described in Fig. 4b.

\section{A is a competitive antagonist of Smo}

To further verify the binding of 0025A to Smo, we performed the Bodipy-cyclopamine competition binding assay, which has been used to detect ligand binding to Smo [32]. We found that known Smo antagonists (cyclopamine, GDC-0449) and 0025A would be able to displace $5 \mathrm{nM}$ Bodipy-cyclopamine from Smo with similar affinities (Fig. 5a). Recent studies have reported that a mutation of Smo (Smo-D473H) was resistance to GDC-0449 therapy [26]. To examine whether 0025A was able to bind with Smo-D473H, we overexpressed Smo-D473H in HEK293 cells and conducted the competition binding assay, which demonstrated that $0025 \mathrm{~A}$ can effectively displace $5 \mathrm{nM}$ Bodipycyclopamine from Smo-D473H. However, GDC-0449 was unable to bind with mutant Smo-D473H at low concentration and represented partial effect at high 
<smiles>Cn1c(-c2ccc(Cl)c(N3CCN(C(=O)CCS(C)(=O)=O)CC3)c2F)nc2ccccc21</smiles>

\section{A}

b<smiles>Nc1ccccc1N</smiles>
$\mathrm{HO}$<smiles>CC(=O)c1ccc(Cl)c(Cl)c1F</smiles>
HOBt EDCI DMAP DMF<smiles>Cn1c(-c2ccc(Cl)c(Br)c2F)nc2ccccc21</smiles><smiles>Nc1ccccc1NC(=O)c1ccc(Cl)c(Br)c1F</smiles><smiles>O=C(O)N1CCNCC1</smiles>

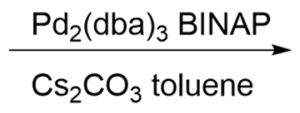<smiles>Cn1c(-c2ccc(Cl)c(N3CCN(C(=O)OC(C)(C)C)CC3)c2F)nc2ccccc21</smiles>

$\mathrm{HCl}$ in dioxane<smiles>Cn1c(-c2ccc(Cl)c(N3CCNCC3)c2F)nc2ccccc21</smiles><smiles>CS(=O)(=O)CCC(=O)O</smiles><smiles>Cn1c(-c2ccc(Cl)c(N3CCN(C(=O)CCS(C)(=O)=O)CC3)c2F)nc2ccccc21</smiles>

Fig. 4 Chemical structure and synthesis of compound 0025A. a Structure of compound 0025A. b Synthesis of compound 0025A

concentration consistent with previous reports $[33,34]$ (Fig. 5b). These results indicate that $0025 \mathrm{~A}$ can compete with cyclopamine to bind with wild-type Smo and Smo-D473H receptor.

\section{Inhibition of Sonic hedgehog signaling}

We next tested the inhibitory effect of 0025A on Sonic hedgehog (Shh) signaling. Previous studies have reported that Smo mediates Shh signaling pathway by locating on 

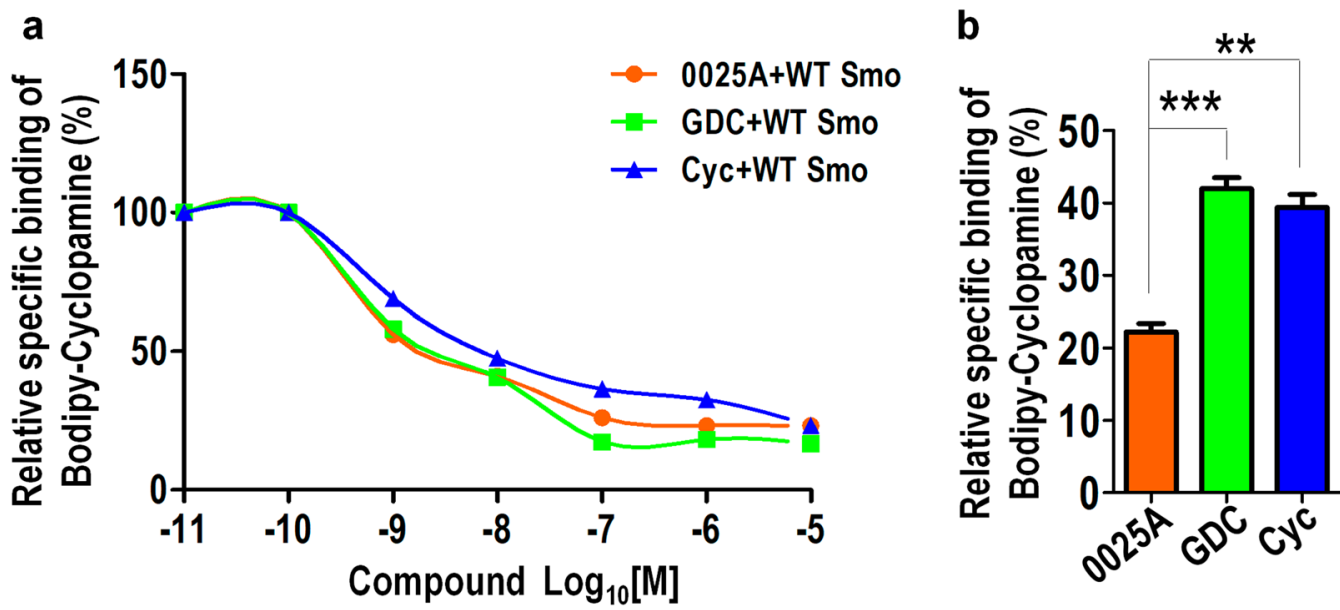

Fig. 5 0025A competitively replaces Bodipy-cyclopamine binding to wild-type Smo and mutant Smo-D473H. a Competitive binding of Bodipy-cyclopamine to wild-type Smo with different concentration of Smo antagonists: 0025A, GDC-0449 (GDC), cyclopamine (Cyc). The Bodipy-cyclopamine competitive assay was performed in HEK293 cells transiently transfected with human wild-type Smo. b Competitive binding of Bodipy-cyclopamine to mutant Smo with $10^{-6} \mathrm{M}(1 \mu \mathrm{M})$ Smo antagonists. The Bodipy-cyclopamine competitive assay was performed in HEK293 cells transiently transfected with human mutant Smo-D473H. The results of Bodipy-cyclopamine binding (green) were analyzed by flow-cytometry. All data are means \pm SEM (student's t-test). ${ }^{* *} P<0.01,{ }^{* * *} P<0.001$

primary cilia [35, 36]. To examine whether 0025A regulated the Smo primary cilia accumulation, we treated the $\mathrm{Ptch}^{-1-}$ MEF cells with DMSO, $10 \mu \mathrm{M}$ GDC-0449, and $10 \mu \mathrm{M} 0025 \mathrm{~A}$ for $24 \mathrm{~h}$, and immunostained the cells with antibodies against Smoothened and ARL 13B, a marker for primary cilia. We observed that compared to DMSO control, 0025A inhibited Smo primary cilia accumulation similar to the effect of the positive control GDC-0449 which could also suppress Smo primary cilia accumulation (Fig. 6a, b).

It is known that Gli1 is the downstream target gene of Shh signaling, which serves as a readout of Shh signaling pathway activity $[37,38]$. To verify the inhibition of 0025A on Shh signaling, we used N-Shh conditioned medium (Shh-CM) or a known Smo agonist SAG to enhance Gli1 transcription. We firstly prepared Shh-CM and explored the optimal effective concentration of SAG through a gradient concentration treatment, which is $100 \mathrm{nM}$. Then we stimulated the serum-starved NIH3T3 cells with $20 \%$ Shh-CM or $100 \mathrm{nM} \mathrm{SAG}$, and found the mRNA level of Gli1 increased fourfold and threefold, respectively (Figs. 7a, 8a). To examine the inhibitory role of $0025 \mathrm{~A}$, we induced the serum-starved NIH3T3 cells by $20 \%$ Shh-CM with vehicle, $0025 \mathrm{~A}(0.01,0.1,1,10 \mu \mathrm{M})$ or GDC-0449 $(1 \mu \mathrm{M})$ for $24 \mathrm{~h}$, and observed that 0025A dose-dependently reduced the mRNA and protein level of Gli1. The positive control GDC-0449 could also suppress the expression of Gli1 (Fig. 7b-d).

Furthermore, we demonstrated that Smo agonist SAG stimulated Shh activitiy could be suppressed by 0025A using similar approaches as Shh-CM (Fig. 8b-d). In addition, we also detect the expression of Ptch1, which is another target gene of Hh signaling pathway [39], and found that 0025A could dose-dependently inhibit the mRNA level of Ptch1 induced by $20 \%$ Shh-CM (Additional file 1: Fig. S1). Taken together, the above results indicate that $0025 \mathrm{~A}$ can act as a potent inhibitor and dose-dependently inhibit target gene expression of the Shh signaling pathway.

\section{A inhibits hair regrowth and hair follicle morphogenesis}

Reports have demonstrated that Shh signaling is closely related to regulate hair follicle morphogenesis [5, 40, 41]. To confirm the inhibitory effect of 0025A on Shh signaling in vivo, we shaved the dorsal hair of 8 week female C57BL/6 mice and depilated with Nair, which could induce hair regrowth into anagen phase of the hair follicles. After depilation, we treated topical skin areas with vehicle and $0025 \mathrm{~A}$ once daily for 14 consecutive days and observed the pigment formation and hair regrowth. The photographs were taken at 10 and 14 days. We found that skin became more gray (hair) in vehicle treated mice on 10 days. In addition, most of hair in vehicle treated mice grew back on 14 days. However, hair growth was largely arrested in 0025A treated group (Fig. 9a). Consistent with the gross phenotype, the histological analysis indicated that the pigment formation and hair follicle morphogenesis was blocked in 0025A treated group (Fig. 9b). Besides, we also observed 0025A inhibited the expression 
a
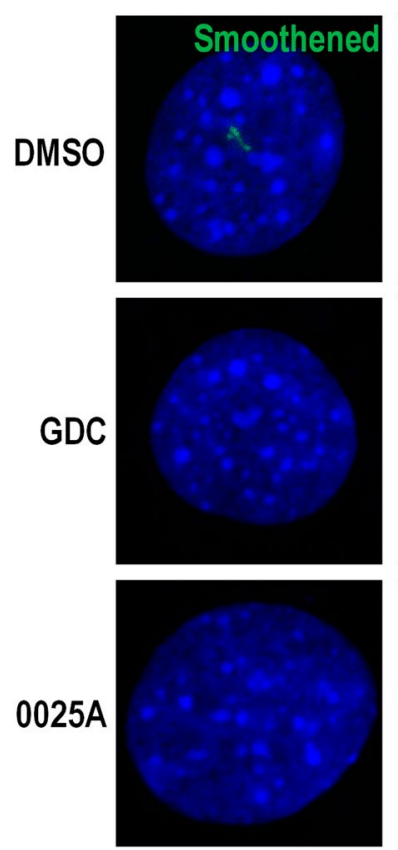
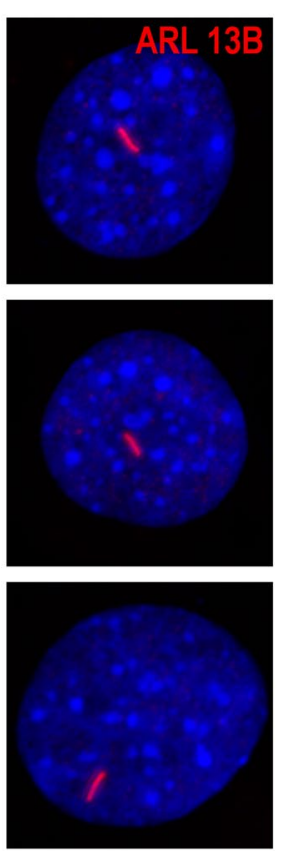

b
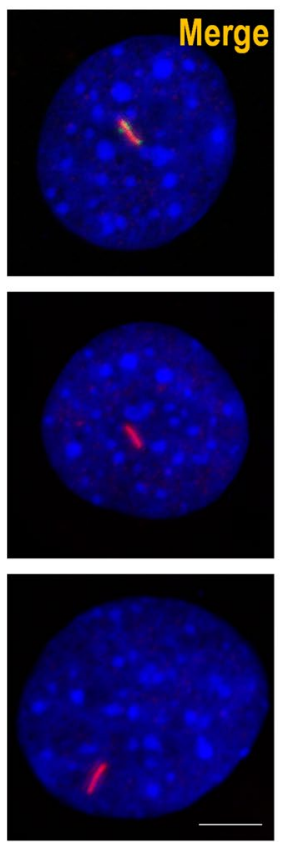

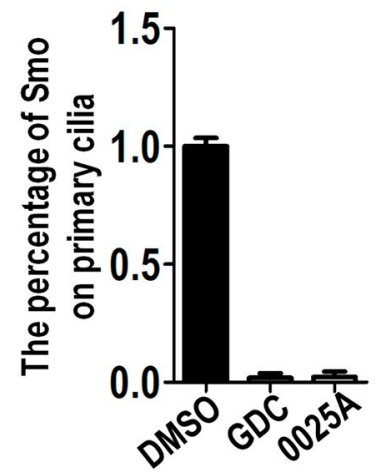

Fig. 6 0025A inhibits the accumulation of Smo on primary cilia. a Serum-starved Ptch ${ }^{-1-}$ MEF cells were treated with DMSO, $10 \mu M$ GDC-0449 (GDC) and $10 \mu \mathrm{M} 0025 \mathrm{~A}$ for $24 \mathrm{~h}$ at $37^{\circ} \mathrm{C}$. Then the cells stained with antibodies against Smoothened (Green) and ARL 13B (Red), a marker for primary cilia. b Percentage of Smo on primary cilia was quantitated $(n=100)$. Scale bar, $5 \mu m$ of Gli1 in hair follicles in the dorsal skin sections by the immunostaining of Gli1 (Additional file 2: Fig. S2). These results demonstrated that 0025A could suppress Shh signaling mediated hair growth in vivo.

\section{Discussion}

Abundant evidences demonstrate that excessive Hh signaling induce the development of many cancers such as the advanced BCC and MB. The seven-transmembrane protein $\mathrm{Smo}$ is the main transducer of Hh signaling pathway and can be used as an important drug target. Therefore, many Smo inhibitors have been under investigation in clinical trials. Among them, GDC-0449 (vismodegib) and LDE-225 (sonidegib) were approved by FDA for treatment of advanced BCC in 2012 and 2015, respectively. As we known, acquired drug resistance is the main obstacle of first generation of Smo inhibitors. According to the clinical trials, GDC-0449 and LDE-225 emerged drug resistance because of the $\mathrm{D} 473 \mathrm{H}$ mutation in Smo $[27,39]$. Thus far, there are no available drugs for treatment of Hh-related diseases, which inspires a surge of Smo inhibitor researches.

In this study, we made use of the Smo/ßarr2-GFP highthroughput assay platform, and screened Smo inhibitors in our propriety small molecules library with the concentration of $5 \mu \mathrm{M}$. Through this effort, we discovered several active hits under screening including 0025A. In the Smo/ßarr2-GFP internalization assay, we found 0025A was the most effective antagonist and be able to inhibit the cellular puncta of $\beta$ arr2-GFP at the nano level. In addition, when we used Shh-CM or SAG to enhance Gli1 transcription, we observed that 0025A can act as a potent inhibitor and dose-dependently inhibit target gene Gli1 expression. At the same time, we have confirmed that $0025 \mathrm{~A}$ would act on Smo receptor to inhibit $\mathrm{Hh}$ signaling pathway. Moreover, this lead compound also could interact with mutated Smo-D473H in contrast to GDC-0449 demonstrated by using Bodipy-cyclopamine competition binding assay. 0025A will provide a new tool to study the Smo-D473H mediated drug resistance and a candidate to treat the drug resistance to improve the cancer therapeutic success.

In addition, reports have demonstrated that Hh signaling is closely related to regulate hair follicle morphogenesis. In this study, we revealed that $0025 \mathrm{~A}$ could inhibit the pigment formation, hair follicle morphogenesis and Hh-induced hair growth after depilation, further proving the inhibition of $0025 \mathrm{~A}$ on Hh signaling pathway and indicating that $0025 \mathrm{~A}$ could penetrate the skin barrier and might be suitable for the treatment of BCC. Next, the therapeutic effect of $0025 \mathrm{~A}$ on $\mathrm{BCC}$ and $\mathrm{MB}$ will be further studied in vitro and in vivo. These studies would 
a

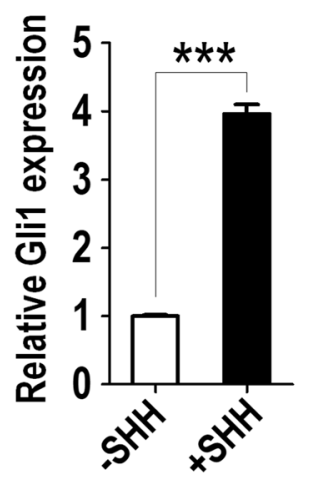

C

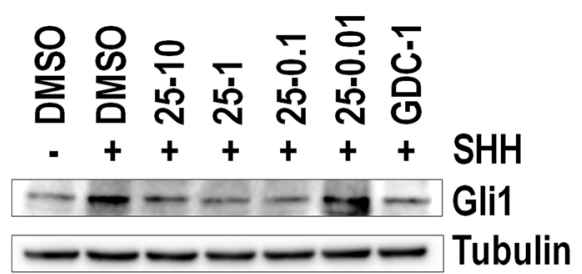

b

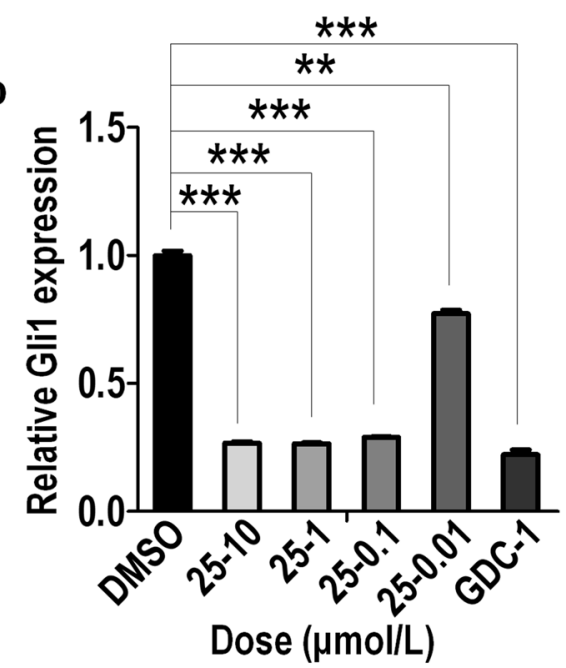

d

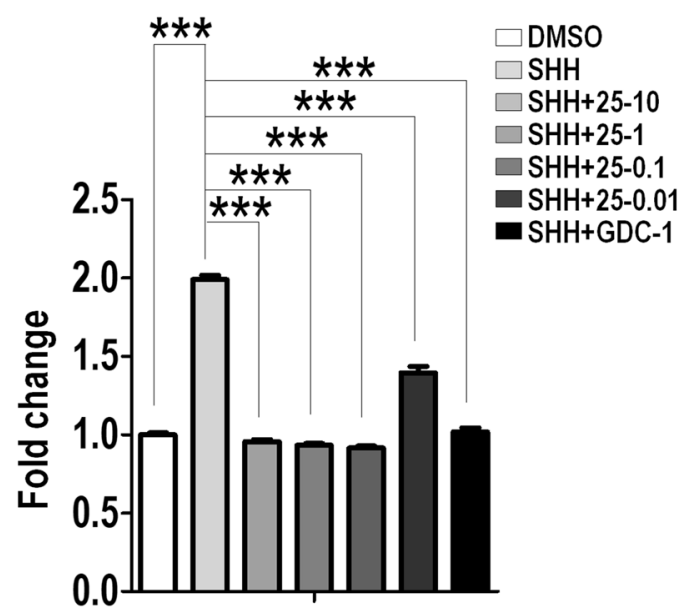

Fig. 7 0025A inhibits the expression of Gli1 induced by Shh-CM. a Serum-starved NIH3T3 cells were treated with Shh-CM for $24 \mathrm{~h}$. Cells were analyzed for mRNA levels of Gli1. b-c Serum-starved NIH3T3 cells were treated by Shh-CM with vehicle, different concentration of $0025 \mathrm{~A}$, or 1 MM GDC-0449 (GDC-1) for $24 \mathrm{~h}$. Cells were analyzed for mRNA levels (b) and the protein levels (c) of Gli1. d Quantitation of Gli1 protein levels normalized to Tubulin loading control. All data are means \pm SEM (student's t-test). ${ }^{* *} P<0.01,{ }^{* * *} P<0.001$

provide basis for future clinical trials and may provide a new therapy for patients with cancers resulted from abnormal Hh activities.

\section{Conclusion}

In summary, we identify 0025A as a potent Smo antagonist of Hh signaling by using the Smo/ßarr2-GFP highthroughput screening platform. In this study, we show that $0025 \mathrm{~A}$ is capable of interacting with wild-type Smo or mutant Smo-D473H and reduce the accumulation of Smo on primary cilia and the expression of Gli upon Hh stimulation. These findings not only provide a new approach to study the insights into mechanisms underlying drug resistance in refractory cancers, but also layout a foundation for developing second generation of Smo inhibitor therapy.

\section{Materials and methods}

\section{Chemicals}

0025A was synthesized by Bellen. Smo agonist (SAG) was synthesized by YuezhiKangtai Biomedicines (Beijing, China). GDC-0449 and Cyclopamine were purchased from Cayman. Bodipy-cyclopamine was purchased from Biovision.

\section{$\mathrm{N}$-Shh conditioned medium}

$\mathrm{N}$-Shh conditioned medium was prepared by transfection of pRK5-ShhN plasmid into 293FT cells. The medium 
a

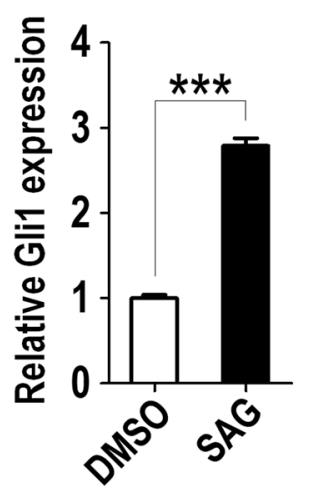

C

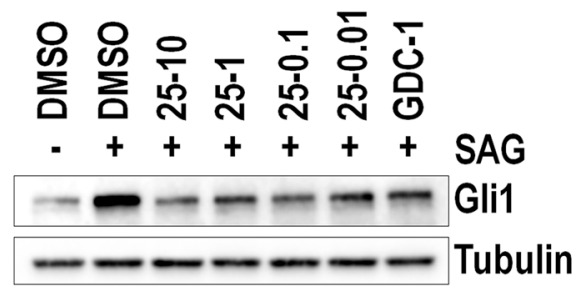

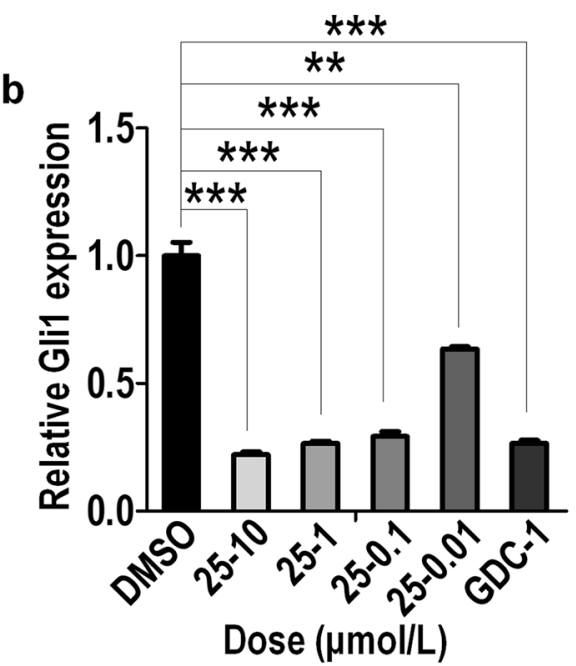

d

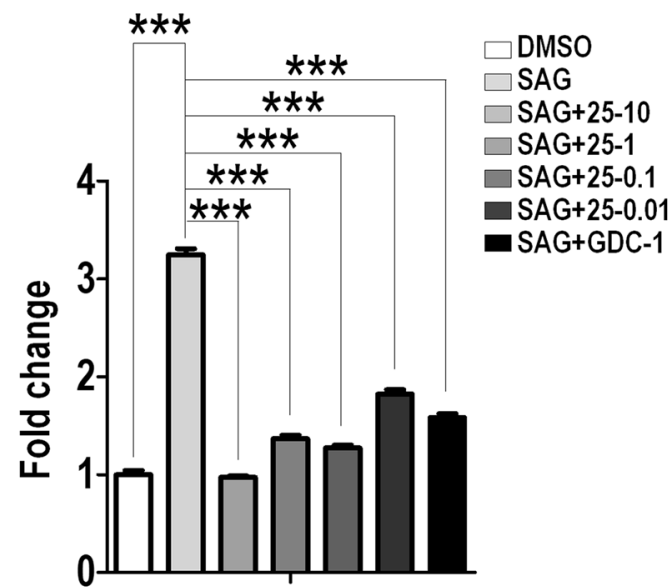

Fig. 8 0025A inhibits the expression of Gli1 induced by SAG. a Serum-starved NIH3T3 cells were induced with DMSO or SAG for $24 \mathrm{~h}$. Cells were analyzed for mRNA levels of Gli1. b, c Serum-starved NIH3T3 cells were induced by $10^{-7} \mathrm{M}$ (100 nM) SAG with vehicle, different concentration of 0025A, or $1 \mu \mathrm{M}$ GDC-0449 (GDC-1) for $24 \mathrm{~h}$. Cells were analyzed for mRNA levels (b) and the protein levels (c) of Gli1. d Quantitation of Gli1 protein levels normalized to Tubulin loading control. All data are means \pm SEM (student's t-test). ${ }^{* *} P<0.01,{ }^{* * *} P<0.001$

was harvested at $24 \mathrm{~h}$ and $48 \mathrm{~h}$ after transfection, pooled and centrifuged at $1000 \mathrm{rpm}$ for $10 \mathrm{~min}$. The supernatant was stored at $4{ }^{\circ} \mathrm{C}$ until used.

\section{Cell culture, plasmids, and western blotting}

293FT, NIH3T3, U2OS and $\mathrm{PTCH}^{-1-}$ MEF cells were cultured in DMEM (Gibco) supplemented with $10 \%$ fetal bovine serum (Hyclone). Barr2-GFP, WT Smo and Smo-633 mutant have been previously described [31]. For standard assay of 0025A effect on Gli1 expression, NIH3T3 cells were plated in 12 -well plate at $2 \times 10^{5}$ per well for overnight. On the next day, the cells were starved in DMEM containing $0.5 \%$ FBS for $1 \mathrm{~h}$ at $100 \%$ confluence, then stimulated with $20 \%$ Shh-CM or $100 \mathrm{nM}$ SAG without or with different concentration of 0025A. $24 \mathrm{~h}$ later, cells were lysed with cell lysis buffer consisting of $50 \mathrm{mM}$ Tris-HCl, PH 7.4, $100 \mathrm{mM} \mathrm{NaCl}, 2 \mathrm{mM}$ EDTA, $1 \%$ NP40, protease inhibitors, and centrifuged with at $12,000 \mathrm{rpm}$ for $10 \mathrm{~min}$ at $4{ }^{\circ} \mathrm{C}$. Cell lysates were collected and immunoblotted with following antibodies: Gli1 (CST, 2534s, 1:1000); Tubulin (CST, 3873s, 1:3000).

\section{Immunostaining}

For tissue staining, dorsal skin were fixed with $4 \%$ paraformaldehyde, dehydrated in graded ethanol series and embedded in paraffin. Sections of $5 \mu \mathrm{m}$ thickness were prepared by Leica RM2255 rotary microtome and used for immunostaining after deparaffinization. For cell staining, $\mathrm{Ptch}^{-/-}$MEF cells cultured on cover-slips were fixed with $4 \%$ paraformaldehyde, blocked with $5 \%$ BSA 

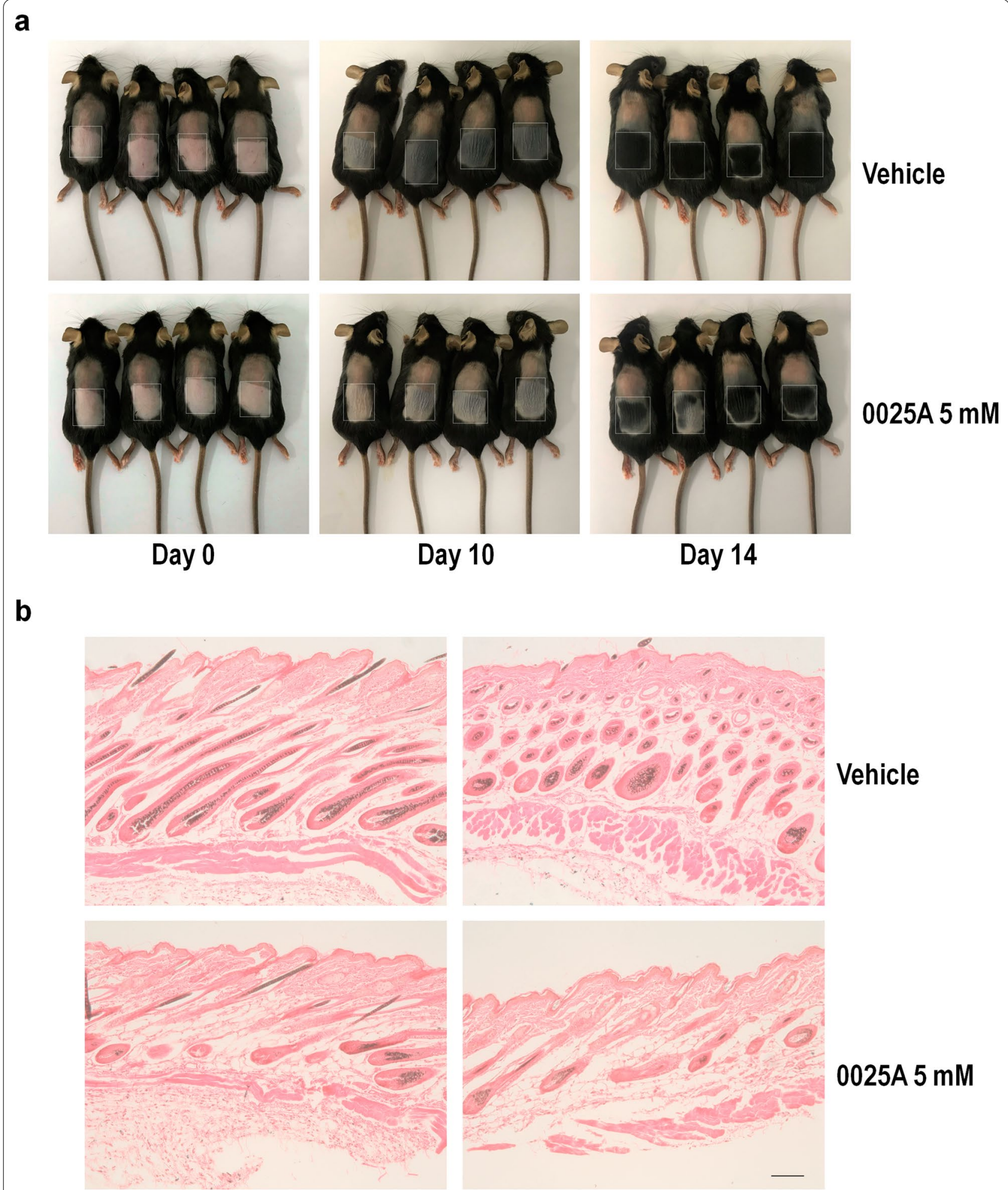

0025A $5 \mathrm{mM}$

Fig. 9 0025A inhibits Hh-dependent hair growth and hair follicle morphogenesis after depilation. a Eight-week old female C57BL/6 mice were shaved. Then the bottom half of dorsal region were depilated with Nair and treated once daily with $30 \mu \mathrm{L}$ of vehicle control $(95 \%$ acetone/5\% DMSO) or 5 mM Smo antagonist 0025A for 14 consecutive days. The photos were taken on 0 Day, 10 Days and 14 Days after depilation. The dotted boxes represented the depilated area. $\mathbf{b}$ Hematoxylin and eosin staining on dorsal skin sections (vehicle and 0025A, n=3). Scale bar, $10 \mu \mathrm{m}$ 
for $1 \mathrm{~h}$ and incubated overnight with primary antibody. The following antibodies were used for immunostaining: Smoothened (Santa Cruz, sc-166685, 1:100); ARL 13B (Proteintech, 17711-1-AP, 1:100); Gli1 (Proteintech, 66905-1-Ig, 1:200). The secondary antibodies conjugated with Alexa Fluor 488 or 568 were purchased from Invitrogen, those conjugated with horse radish peroxidase (HRP) using DAB as chromogen from Cwbio. Sections were photographed by LSM710 Zeiss confocal microscope and analyzed with Image J software.

\section{RNA isolation, reverse transcription and real-time PCR}

Cells were harvested and extracted total RNA using the TRIzol reagent (Thermo), and reverse transcription was performed with PrimeScript ${ }^{\mathrm{TM}} \mathrm{RT}$ reagent Kit (TaKaRa). Real-time PCR was carried out according to the protocol of the manufactory. The primers for real-time PCR were mouse Gli1, F: 5'-CTCAAACTGCCCAGCTTAACC.

C-3', R: 5'-TGCGGCTGACTG TGTAAGCAGA-3'; Actin, F: 5'-GCAAGTGCTTC.

TAGGCGGAC-3', R: 5'-AAGAAAGGGTGTAAAACG CAGC-3'.

\section{Construction of Smo D473H mutagenesis}

Flag Smo-D473H point mutation was established by using Fast Mutagenesis System (TransGen Biotech). Primers were as follows: F: 5'-AGCTGCCACTTCTAC.

CACTTCTTCAA-3', R: 5'-GGTAGAAGTGGCAGC TGAAGGTAATG-3'.

\section{Bodipy-cyclopamine binding assay}

Human Flag Smo WT or Smo mutant (D473H) was transfected in HEK293 cells. 24 h later, the HEK293 cells were trypsinized, washed in phenol-red free DMEM supplemented with $0.5 \%$ fetal bovine serum, fixed with $4 \%$ paraformaldehyde for $10 \mathrm{~min}$ at room temperature and incubated with $5 \mathrm{nM}$ Bodipy-cyclopamine and different concentration of indicated compounds for $2 \mathrm{~h}$ at $37{ }^{\circ} \mathrm{C}$. Then the treated cells were centrifuged and the fluorescent signals were analyzed by flow cytometry.

\section{Animal studies}

The animal studies were performed as previously described [30]. Briefly, female C57BL/6 mice (aged 7 to 8 weeks) were shaved dorsal hair and the bottom half of shaved area was depilated with Nair for $2 \mathrm{~min}$. After depilation, the mice were topically treated with $30 \mu \mathrm{L}$ of $5 \mathrm{mM}$ 0025A dissolved in a vehicle of $95 \%$ acetone/5\% DMSO or the vehicle once daily for 14 consecutive days and observed the pigment formation and hair regrowth. During the experimental procedures, the mice were anesthetized by $3 \%$ isoflurane and the studies were performed according to the ethical principles of animal welfare of Beijing Institute of Neurosurgery.

\section{Statistical analysis}

All statistical analyses were acquired from at least three independent experiments, and values were expressed as means $\pm S E M$, and two-sample comparisons were performed using an unpaired Student's $t$ test. ${ }^{*} P<0.05$ was considered as statistical significance. All statistical analyses were presented using Prism software (GraphPad Software, Inc, CA).

\section{Supplementary Information}

The online version contains supplementary material available at https://doi. org/10.1186/s13578-021-00558-9.

Additional file 1: Fig. S1. 0025A inhibits the expression of Ptch1 induced by Shh-CM. a Serum-starved NIH3T3 cells were treated with Shh-CM for $24 \mathrm{~h}$. Cells were analyzed for mRNA levels of Ptch1. b Serum-starved $\mathrm{NIH} 3 \mathrm{~T} 3$ cells were treated by Shh-CM with vehicle, different concentration of 0025A, or $1 \mu$ M GDC-0449 (GDC-1) for $24 \mathrm{~h}$. Cells were analyzed for mRNA levels of Ptch1. All data are means \pm SEM (student's t-test). ${ }^{*} P<0.05$, ${ }^{*} P<0.01$, ns, not significant.

Additional file 2: Fig. S2. 0025A inhibits the expression of Gli1 in hair follicle. Dorsal skin section samples treated with vehicle or $0025 \mathrm{~A}$ were stained with anti-Gli1 antibody for Gli1 expression. Scale bar, $10 \mu \mathrm{m}$.

\section{Abbreviations}

Hh: Hedgehog; Ptch 1: Patched1; Smo: Smoothened; BCC: Basal cell carcinoma; MB: Medulloblastoma; ßarr2-GFP: ßArrestin2-GFP; Shh: Sonic hedgehog; ShhCM: N-Shh conditioned medium; Cyc: Cyclopamine.

\section{Acknowledgements}

We would like to thank Dr. Feng Yang for discussion and critical reading, Dr. Yaqing Wang for her valuable advices, Dr. Minghui Yao for her help with construction of stable cell line.

\section{Authors' contributions}

JF and WC designed the project, analyzed the data and wrote the manuscript. $\mathrm{HL}$ contributed to the cloning of Smo mutant and real-time PCR. LK performed experiments. ZZ performed experiments. WH provided the resources. $\mathrm{CL}$ contributed to detecting the accumulation of Smo primary cilia. YW and SC analyzed the data and wrote the manuscript. All authors read and approved the final manuscript.

\section{Funding}

This work was supported by Grants from Beijing Tiantan Hospital, Capital Medical University (RCYJ-20190124) and from National Science Foundation of China (81672748 and 81871936) to Steven Y. Cheng.

Availability of data and materials

All data generated or analyzed during this study are included in this published article.

\section{Ethics approval and consent to participate}

Not applicable.

\section{Consent for publication \\ Not applicable.}

\section{Competing interests}

The authors declare no conflict of interest. 


\section{Author details}

${ }^{1}$ China National Clinical Research Center for Neurological Diseases, Beijing Tiantan Hospital, Capital Medical University, Beijing 100070, China. ${ }^{2}$ Beijing Key Laboratory of Translational Medicine for Cerebrovascular Disease, Beijing 100070, China. ${ }^{3}$ Department of Developmental Genetics, School of Basic Medical Sciences, Nanjing Medical University, Nanjing 210000, Jiangsu, China.

Received: 7 December 2020 Accepted: 16 February 2021

Published online: 02 March 2021

\section{References}

1. Ingham PW, McMahon AP. Hedgehog signaling in animal development: paradigms and principles. Genes Dev. 2001;15(23):3059-87.

2. Ishibashi M, McMahon AP. A sonic hedgehog-dependent signaling relay regulates growth of diencephalic and mesencephalic primordia in the early mouse embryo. Development. 2002;129(20):4807-19.

3. Teglund S, Toftgård R. Hedgehog beyond medulloblastoma and basal cell carcinoma. Biochim Biophys Acta. 2010;1805(2):181-208.

4. Pasca di Magliano M, Hebrok M. Hedgehog signalling in cancer formation and maintenance. Nat Rev Cancer. 2003;3(12):903-11.

5. St-Jacques B, Dassule HR, Karavanova I, Botchkarev VA, Li J, Danielian PS, et al. Sonic hedgehog signaling is essential for hair development. Curr Biol. 1998;8(19):1058-68.

6. Gorojankina T. Hedgehog signaling pathway: a novel model and molecular mechanisms of signal transduction. Cell Mol Life Sci. 2016;73(7):1317-32

7. Pak E, Segal RA. Hedgehog signal transduction: key players, oncogenic drivers, and cancer therapy. Dev Cell. 2016;38(4):333-44.

8. Robbins DJ, Fei DL, Riobo NA. The Hedgehog signal transduction network. Sci Sign. 2012;5(246):6.

9. Ruch JM, Kim EJ. Hedgehog signaling pathway and cancer therapeutics: progress to date. Drugs. 2013;73(7):613-23.

10. Chen W, Ren XR, Nelson CD, Barak LS, Chen JK, Beachy PA, et al. Activitydependent internalization of smoothened mediated by beta-arrestin 2 and GRK2. Science. 2004;306(5705):2257-60.

11. Arensdorf AM, Marada S, Ogden SK. Smoothened regulation: a tale of two signals. Trends Pharmacol Sci. 2016;37(1):62-72.

12. Yang $L$, Xie G, Fan $Q$, Xie J. Activation of the hedgehog-signaling pathway in human cancer and the clinical implications. Oncogene. 2010;29(4):469-81.

13. Wu F, Zhang C, Zhao C, Wu H, Teng Z, Jiang T. Prostaglandin E1 Inhibits GLI2 amplification-associated activation of the hedgehog pathway and drug refractory tumor growth. Cancer Res. 2020;80(13):2818-32.

14. Hahn H, Wicking C, Zaphiropoulous PG, Gailani MR, Shanley S, Chidambaram A, et al. Mutations of the human homolog of Drosophila patched in the nevoid basal cell carcinoma syndrome. Cell. 1996;85(6):841-51.

15. Rimkus TK, Carpenter RL, Qasem S, Chan M, Lo HW. Targeting the sonic hedgehog signaling pathway: review of smoothened and GLI inhibitors. Cancers (Basel). 2016;8:2.

16. Thompson MC, Fuller C, Hogg TL, Dalton J, Finkelstein D, Lau CC, et al. Genomics identifies medulloblastoma subgroups that are enriched for specific genetic alterations. J Clin Oncol. 2006;24(12):1924-31.

17. Kool M, Jones DT, Jager N, Northcott PA, Pugh TJ, Hovestadt V, et al. Genome sequencing of $\mathrm{SHH}$ medulloblastoma predicts genotype-related response to smoothened inhibition. Cancer Cell. 2014;25(3):393-405.

18. Samkari A, White J, Packer R. SHH inhibitors for the treatment of medulloblastoma. Expert Rev Neurother. 2015;15(7):763-70.

19. Ishii T, Shimizu Y, Nakashima K, Kondo S, Ogawa K, Sasaki S, et al. Inhibition mechanism exploration of investigational drug TAK-441 as inhibitor against Vismodegib-resistant Smoothened mutant. Eur J Pharmacol. 2014;723:305-13.

20. Lee MJ, Hatton BA, Villavicencio EH, Khanna PC, Friedman SD, Ditzler S, et al. Hedgehog pathway inhibitor saridegib (IPI-926) increases lifespan in a mouse medulloblastoma model. Proc Natl Acad Sci USA. 2012;109(20):7859-64.

21. Patel SS, Tomar S, Sharma D, Mahindroo N, Udayabanu M. Targeting sonic hedgehog signaling in neurological disorders. Neurosci Biobehav Rev. 2017;74(Pt A):76-97.
22. Kieran MW. Targeted treatment for sonic hedgehog-dependent medulloblastoma. Neuro Oncol. 2014;16(8):1037-47.

23. Lou E, Schomaker M, Wilson JD, Ahrens M, Dolan M, Nelson AC. Complete and sustained response of adult medulloblastoma to first-line sonic hedgehog inhibition with vismodegib. Cancer Biol Ther. 2016;22:1-7.

24. Von Hoff DD, LoRusso PM, Rudin CM, Reddy JC, Yauch RL, Tibes R, et al. Inhibition of the hedgehog pathway in advanced basal-cell carcinoma. N Engl J Med. 2009;361(12):1164-72.

25. LoRusso PM, Rudin CM, Reddy JC, Tibes R, Weiss GJ, Borad MJ, et al. Phase I trial of hedgehog pathway inhibitor vismodegib (GDC-0449) in patients with refractory, locally advanced or metastatic solid tumors. Clin Cancer Res. 2011;17(8):2502-11.

26. Robinson GW, Orr BA, Wu G, Gururangan S, Lin T, Qaddoumi I, et al. Vismodegib exerts targeted efficacy against recurrent sonic hedgehogsubgroup medulloblastoma: results from phase II pediatric brain tumor consortium studies PBTC-025B and PBTC-032. J Clin Oncol. 2015;33(24):2646-54.

27. Dijkgraaf GJ, Alicke B, Weinmann L, Januario T, West K, Modrusan Z, et al. Small molecule inhibition of GDC-0449 refractory smoothened mutants and downstream mechanisms of drug resistance. Cancer Res. 2011;71(2):435-44.

28. Atwood SX, Sarin KY, Whitson RJ, Li JR, Kim G, Rezaee M, et al. Smoothened variants explain the majority of drug resistance in basal cell carcinoma. Cancer Cell. 2015;27(3):342-53.

29. Luttrell LM, Lefkowitz RJ. The role of beta-arrestins in the termination and transduction of G-protein-coupled receptor signals. J Cell Sci. 2002;115(Pt 3):455-65.

30. Wang J, Mook RA Jr, Lu J, Gooden DM, Ribeiro A, Guo A, et al. Identification of a novel Smoothened antagonist that potently suppresses Hedgehog signaling. Bioorg Med Chem. 2012;20(22):6751-7.

31. Wang J, Lu J, Bond MC, Chen M, Ren XR, Lyerly HK, et al. Identification of select glucocorticoids as Smoothened agonists: potential utility for regenerative medicine. Proc Natl Acad Sci USA. 2010;107(20):9323-8.

32. Chen JK, Taipale J, Young KE, Maiti T, Beachy PA. Small molecule modulation of Smoothened activity. Proc Natl Acad Sci U S A. 2002;99(22):14071-6.

33. Yauch RL, Dijkgraaf GJ, Alicke B, Januario T, Ahn CP, Holcomb T, et al. Smoothened mutation confers resistance to a Hedgehog pathway inhibitor in medulloblastoma. Science. 2009;326(5952):572-4.

34. Zhu M, Wang H, Wang C, Fang Y, Zhu T, Zhao W, et al. L-4, a well-tolerated and orally active inhibitor of hedgehog pathway, exhibited potent anti-tumor effects against medulloblastoma in vitro and in vivo. Front Pharmacol. 2019;10:89.

35. Wu VM, Chen SC, Arkin MR, Reiter JF. Small molecule inhibitors of Smoothened ciliary localization and ciliogenesis. Proc Natl Acad Sci USA. 2012;109(34):13644-9.

36. Wang Y, Zhou Z, Walsh CT, McMahon AP. Selective translocation of intracellular Smoothened to the primary cilium in response to Hedgehog pathway modulation. Proc Natl Acad Sci USA. 2009;106(8):2623-8.

37. Chen J, Lv H, Hu J, Ji M, Xue N, Li C, et al. CAT3, a novel agent for medulloblastoma and glioblastoma treatment, inhibits tumor growth by disrupting the Hedgehog signaling pathway. Cancer Lett. 2016;381(2):391-403.

38. Skoda AM, Simovic D, Karin V, Kardum V, Vranic S, Serman L. The role of the Hedgehog signaling pathway in cancer: a comprehensive review. Bosn J Basic Med Sci. 2018;18(1):8-20.

39. Li QR, Zhao H, Zhang XS, Lang H, Yu K. Novel-smoothened inhibitors for therapeutic targeting of naïve and drug-resistant hedgehog pathwaydriven cancers. Acta Pharmacol Sin. 2019;40(2):257-67.

40. Oro $A E$, Higgins K. Hair cycle regulation of Hedgehog signal reception. Dev Biol. 2003;255(2):238-48.

41. Stenn KS, Paus R. Controls of hair follicle cycling. Physiol Rev. 2001;81(1):449-94.

\section{Publisher's Note}

Springer Nature remains neutral with regard to jurisdictional claims in published maps and institutional affiliations. 